\title{
Antihypertensive Activity of Fermented Milk Containing Various Aqueous Herbal Extracts
}

\author{
Kanik $^{1,2}$, Gauri Jairath ${ }^{1}$, Birbal Singh ${ }^{1}$, Jyoti B. Dhar ${ }^{1}$, Rinku Sharma ${ }^{1}$, \\ Devi Gopinath $^{1}$, Neelam Sharma ${ }^{2}$, Gorakh Mal ${ }^{1, *}$ \\ ${ }^{1}$ ICAR-Indian Veterinary Research Institute, Regional Station, Palampur (HP), India. \\ ${ }^{2}$ CSK HPKVV, Palampur (HP), India.
}

How to cite this paper: Kanik, Gauri
Jairath, Birbal Singh, Jyoti B. Dhar, Rinku
Sharma, Devi Gopinath, Neelam Sharma,
Gorakh Mal. (2021) Antihypertensive
Activity of Fermented Milk Containing
Various Aqueous Herbal Extracts. Interna-
tional Journal of Food Science and Agri-
culture, 5(2), 326-331.

DOI: $10.26855 /$ ijfsa.2021.06.018

Received: April 16, 2021

Accepted: May 20, 2021

Published: June 9, 2021

*Corresponding author: Gorakh Mal, ICAR-Indian Veterinary Research Institute, Regional Station, Palampur (HP), India.

Email: gorakh14@yahoo.com

\begin{abstract}
The present study was conducted with the objective to enhance the Angiotensin converting enzyme (ACE, EC 3.4.15.1) inhibitory activity of indigenous cattle milk through supplementation with various herbal extracts. The fermented milk supplemented with aqueous extracts of fruits of harad (Terminalia chebula), baheda (Terminalia bellirica), amla (Phyllanthus emblica) and bark of arjuna (Terminalia arjuna) were evaluated for ACE inhibitory activity. Maximum (37.92 $\pm 0.72 \%)$ ACE inhibitory activity was observed in pepsin-digest of fermented milk containing aqueous harad extract, whereas minimum (25.37 $\pm 0.59 \%)$ ACE inhibitory activity was observed in fermented milk containing aqueous extract of amla. Undigested samples of fermented milk containing aqueous arjuna extract exhibited significantly higher ACE inhibitory activity $(19.70 \pm 0.58 \%)$, followed by amla $(17.00 \pm 0.70 \%)$, and baheda (16.59 \pm 0.94\%). Fermented milk containing aqueous harad extract had significantly lower value $(14.97 \pm 0.62 \%)$. No significant difference was found between fermented milk containing aqueous extracts amla and extracts of baheda. Based on the results described above, we surmise that herbal supplemented fermented milk had better antihypertensive activity.
\end{abstract}

\section{Keywords}

ACE (Angiotensin Converting Enzyme) Activity, Fermented Milk Containing Various Aqueous Herbal Extracts, Antihypertensive Activity

\section{Introduction}

Indigenous cattle breed of Himachal Pradesh, India known as 'Himachali Pahari cow' is distributed in 7 districts including Chamba, Mandi, Kullu, Kangra, Sirmour, Kinnaur \& Lahaul Spiti, and registered as a unique species with distinct features/qualities. Cattle milk proteins possess beneficial attributes including opoid, immunomodulatory, antimicrobial and antioxidant activities. Angiotensin converting enzyme (ACE) plays a key role in blood pressure control by producing the vasoconstrictor angiotensin II. Significant goal of hypertension prevention is to inhibit ACE with natural inhibitors to avoid the side-effect of synthetic medicines [1]. Hypertension is a significant risk factor for heart failure, stroke, Myocardial infarction, atherosclerosis, kidney diseases and peripheral arterial disease as well as chronic kidney disease [2-5]. Six classes of drugs (angiotensin II receptor blockers, ACE inhibitors, diuretics, calcium channel blockers, $\alpha$-adrenergic antagonist, and $\beta$-blockers) are active for anti-hypertension [6]. ACE inhibitors are more commonly used because they protect the target organ while having no negative effects on glycolipid metabolism.

ACE is a metalloproteinase also known as kinase II which contains two zinc-catalytically active sites and can simultaneously affect the renin-angiotensin (RAS) system and the Kallikrein/kininine (KKS) system [7]. Under the combined action of renin and ACE, inactive angiotensin-I is hydrolyzed to angiotensin-II with successful vasoconstrictor action in the RAS system, resulting in elevated blood pressure. The KKS is an endogenous blood pressure system in which the 
ACE inhibits the antihypertensive effect by bradykinin deactivation. The role of ACE in both systems eventually led to a higher blood pressure [8-12].

Angiotensin I-converting enzyme (ACE) is a key enzyme in regulation of blood pressure through two different reactions in the renin-angiotensin-aldosterone system (RAAS) and the kinin nitric oxide system (KNOS). For this, many synthetic ACE inhibitors, such as captopril, enalapril, fosinopril, lisinopril, and ramipril were identified and used for the treatment of hypertension. However, these synthetic inhibitors have side effects including coughing, taste disturbance and skin rash [13-14]. Thus, one of the major challenges to today's world healthcare sectors is to identify ACE inhibitors from natural resources.

The assay of ACE inhibitory activity is based on specific binding of TNBS to the primary amine of His-Leu dipeptide produced by hydrolytic cleavage from Hip-His-Leu by ACE, forming TNP-His-Leu (TNP-HL) by desulfitation, followed by formation of a yellow complex with sulfite detected at $420 \mathrm{~nm}$ [15].

Animal proteins, vegetable proteins, and algae are the key sources of food-derived ACE inhibitory peptides that have been identified. A source of ACE inhibitory peptides for animal protein products is milk protein, which includes casein, lactalbumin, and lactoglobulin [16-17].

Hypertension is an important factor in cardiovascular disease. Angiotensin-I-converting enzyme (ACE) inhibitors such as synthetic drugs are commonly used to regulate hypertension. ACE-inhibiting food-borne peptides may be a viable alternative to synthetic drugs. A variety of plant-based peptides have been investigated for their potential ACE inhibitor activity using in vitro and in vivo. These plant based peptides can be generated by extraction of solvents, enzymatic hydrolysis with or without novel methods of food processing, and fermentation. ACE-inhibiting activities of peptides can be affected by their structural features, such as chain length, composition and sequence. ACE-inhibiting peptides should have gastrointestinal stability and enter the cardiovascular system to demonstrate their bioactivity [18].

The lassi, fermented milk product containing angiotensin-I-converting-enzyme (ACE)-inhibitory peptides, was made by using Lactobacillus acidophilus NCDC-15 and the incubation period and simmering effect was also optimized for production of ACE-inhibitory peptides. The biological activity was measured in the supernatant of the fermented milk after centrifugation. The milk fermented by $L$. acidophilus has a high ACE-inhibitory activity because it contained the sequences of $\beta$-casein $(\beta-\mathrm{CN})$ fragment [19].

Nutrition plays an important role in the prevention of cardiovascular disease (CVD) such as atherosclerosis, coronary heart disease, stroke and heart failure [20-22]. According to the World Health Organization (WHO), these diseases are the highest cause of global death (WHO). Hypertension is the most important risk factor for CVDs, a condition in which blood vessels have a persistent increase in pressure. Blood pressure medications, particularly angiotensin-I-converting enzyme inhibitors (ACE; EC 3.4.15.1) are commonly used to control blood pressure in the renin-angiotensin system [22].

Terminalia is a tree species with medicinal properties. Three species of terminalia are Terminalia bellerica ("Baheda”), Terminalia arjuna (“Arjun”) and Terminalia chebula (“Harad”) used in medicine. Emblica officinalis ('Amla') is one of the most important plants in the traditional Ayurvedic medical system as well as in other traditional immunomodulatory, anti-inflammatory, anti-ulcer, hepatoprotective and anti-cancer systems. The fruits are rich in vitamin $\mathrm{C}$ and also in phenol reservoirs, including gallic acid, ellagic acid, quercetin, kaempferol, geranin, furosin, corilagin, gallotanins, emblicanins, flavonoids, glycosides and proanthocyanidins.

Over the past few decades, numerous studies for the treatment of hypertension have been conducted to determine whether blood pressure reduction in middle age reduces the risk of stroke and of CHD. For stroke, the overview provides direct and highly significant evidence that both fatal and non-fatal strokes are prevented within just a few years of blood pressure lowering [3]. The present study was aimed to investigate the in vitro antihypertensive activity of herbal supplemented fermented milk prepared from indigenous hill cattle milk.

\section{Materials and methods}

\subsection{Collection of Milk}

Milk samples of indigenous cattle were collected from surrounding area of Palampur. The $\mathrm{pH}$ and total titratable acidity of milk were determined and then milk containers were stored in a freezer at $-20^{\circ} \mathrm{C}$ for further use.

\subsection{Collection of herbal plant material}

The bark of Terminalia arjuna (arjuna) and fruits of Terminalia bellerica (baheda), Terminalia chebula (harad) and Emblica officinalis (amla) were collected from the surrounding areas of Palampur. The bark and fruits were dried in hot air oven by maintaining temperature at $37^{\circ} \mathrm{C}$. The dried samples were ground to powdered form. The powdered samples were stored in air tight containers at room temperature for further use.

\subsection{Water extraction of herbal plants}

Dried powdered of Terminalia chebula, Terminalia bellerica, Terminalia arjuna and Emblica officinalis (10 g) was 
suspended in $100 \mathrm{ml}$ of distilled water in separate flasks and incubated overnight in a water bath at $70^{\circ} \mathrm{C}$. Filtered the samples through whatman filter paper no. 1 and filtrate was used as herbal water extract and stored at $-20^{\circ} \mathrm{C}$ till further use.

\subsection{Preparation of starter culture}

Starter culture was prepared by using Lactobacillus rhamnosus (347) bacteria, purchased from National collection of dairy culture (NCDC), NDRI Karnal. The lyophilized Lactobacillus rhamnosus (347) bacterium was re-activated by inoculating the bacterium in MRS (De Man, Rogosa and Sharpe) broth and following the incubation in incubator at $37^{\circ} \mathrm{C}$ for 24 hours. It was again re-inoculated for 3-4 times after that colony inoculated in skim milk. The cultured skim milk $5 \mathrm{~g}$ was introduced in $100 \mathrm{ml}$ boiled milk of indigenous cattle and mixture was incubated for $6-7$ hours at $41^{\circ} \mathrm{C}$ until $\mathrm{pH} 4.5$ and stored in refrigerator at $4^{\circ} \mathrm{C}$.

\subsection{Preparation of fermented milk containing herbal water extracts}

Fermented milk was prepared by adding $10 \mathrm{ml}$ of various herbal water extracts into $85 \mathrm{ml}$ of fresh boiled milk of indigenous cattle and $5 \mathrm{~g}$ of starter culture. The mixture was mixed thoroughly followed by incubation at $41^{\circ} \mathrm{C}$ until $\mathrm{pH}$ was reduced to 4.5. The same procedures were carried out to prepare control fermented milk by using distilled water in place of herbal water extract. Samples were refrigerated at $\left(4^{\circ} \mathrm{C}\right)$ till further use.

\subsection{In vitro enzymatic digestion of fermented milk containing aqueous herbal extracts}

In vitro enzymatic digestion protocol described by [23] with modifications. Yogurt sample $(10 \mathrm{ml})$ was taken. Undigested and digested samples were centrifuged at $12,000 \mathrm{rpm}$ for $30 \mathrm{~min}$ and harvested supernatant was stored at $-20^{\circ} \mathrm{C}$ for analysis.

\subsection{ACE (Angiotensin converting enzyme) inhibitory activity in fermented milk containing aqueous herbal extracts}

ACE assay was estimated using the method that is described by [24] with some modifications.

The assay mixture contained $540 \mu \mathrm{l}$ for control B, $580 \mu \mathrm{l}$ for Control C, $530 \mu \mathrm{l}$ for Control A of $0.1 \mathrm{M}$ sodium borate buffer (pH 8.3), $200 \mu \mathrm{l}$ of $5 \mathrm{mM}$ HHL (Hippuryl-histidyl-leucine), $40 \mu \mathrm{l}$ of ACE enzyme and $10 \mu \mathrm{l}$ of diluted sample (Sample was diluted 10 times with sodium borate buffer $\mathrm{pH}$ 8.3). The reaction was terminated after incubation at $37^{\circ} \mathrm{C}$ for $60 \mathrm{~min}$, through the addition of $300 \mu \mathrm{l}$ of $1 \mathrm{M} \mathrm{HCl}$. After stopping the reaction, $600 \mu \mathrm{L}$ of pyridine was added followed by $300 \mu \mathrm{l}$ of benzene sulphonyl chloride (BSC) and the solution was mixed before cooling down on ice. The absorbance was measured at $410 \mathrm{~nm}$.

\section{Results and Discussion}

Angiotensin converting enzyme (ACE) inhibitory activity in fermented milk containing aqueous herbal plant extracts

The effect of different fermented milk containing aqueous herbal extracts and its in vitro digestion on ACE are presented in Table 1. Angiotensin-converting enzyme (ACE) inhibitory activity can be measured using the substrate hippuryl-L-histidyl-L-leucine (HHL).

Undigested samples of fermented milk containing aqueous arjuna extract exhibited significantly higher ACE inhibitory activity (19.70 $\pm 0.58 \%)$, followed by amla $(17.00 \pm 0.70 \%)$, and baheda $(16.59 \pm 0.94 \%)$ at the significance level of $\mathrm{P}<0.05$. Fermented milk containing aqueous harad extract exhibited significantly lower value $(14.97 \pm 0.62 \%)$. Nevertheless, no significant difference was found between fermented milk containing aqueous extracts amla and extracts of baheda (Table 1).

Table 1. ACE inhibitory activity of fermented milk containing aqueous herbal plant extracts

\begin{tabular}{ccccccc}
\hline \multirow{2}{*}{ S. No. } & Sample & \multicolumn{3}{c}{ ACE (\% inhibition) } \\
& & Control & Harad & Baheda & Amla & Arjuna \\
\hline 1 & Fermented milk (UD) $(\mathrm{n}=8)$ & $10.52^{\mathrm{Dc}} \pm 0.84$ & $14.97^{\mathrm{Cc}} \pm 0.62$ & $16.59^{\mathrm{Bc}} \pm 0.94$ & $17.00^{\mathrm{Bc}} \pm 0.70$ & $19.70^{\mathrm{Ac}} \pm 0.58$ \\
2 & Pepsin digest (PD) $(\mathrm{n}=8)$ & $25.77^{\mathrm{Db}} \pm 0.59$ & $37.92^{\mathrm{Ab}} \pm 0.72$ & $28.60^{\mathrm{Cb}} \pm 0.95$ & $25.37^{\mathrm{Db}} \pm 0.59$ & $34.54^{\mathrm{Bb}} \pm 0.36$ \\
3 & Overnight digest (OD) $(\mathrm{n}=8)$ & $33.06^{\mathrm{Da}} \pm 0.71$ & $48.58^{\mathrm{Aa}} \pm 0.47$ & $49.79^{\mathrm{Aa}} \pm 0.23$ & $45.34^{\mathrm{Ba}} \pm 0.62$ & $41.16^{\mathrm{Ca}} \pm 0.95$ \\
\hline
\end{tabular}

Different upper-case letters correspond to significant differences between the groups $(\mathrm{P} \leq 0.05)$. Different lower-case letters correspond to significant differences within the same group $(\mathrm{P} \leq 0.05)$; $\mathrm{n}=$ number of samples. 


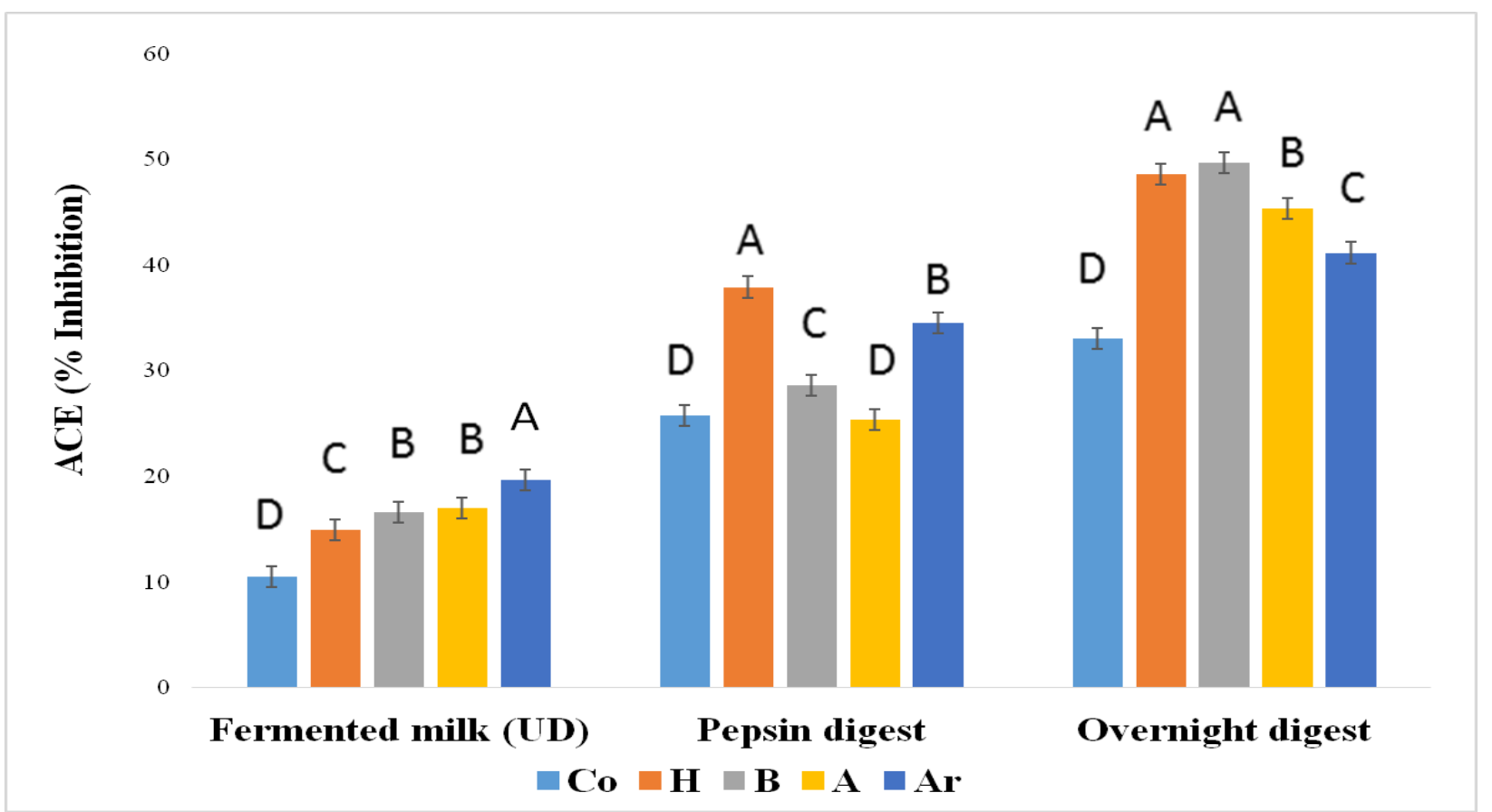

Figure 1. ACE inhibitory activity of fermented milk containing aqueous herbal plant extracts (Co-Control, H-Harad, B-Baheda, A-Amla, Ar-Arjuna). Different upper-case letters correspond to significant differences between the groups (P $\leq$ 0.05)

A substantial increase in ACE $(\mathrm{P}<0.05)$ was observed in pepsin digested fermented milk containing aqueous harad, baheda, amla and arjuna extracts as compared to control. Maximum (37.92 $\pm 0.72 \%)$ ACE inhibitory activity was observed in pepsin-digest of fermented milk containing aqueous harad extract, whereas minimum (25.37 $\pm 0.59 \%)$ ACE inhibitory activity was observed in fermented milk containing aqueous extract of amla (Table 1).

ACE was found to be significantly higher as compared with control $(\mathrm{P}<0.05)$ in overnight digested fermented milk samples containing aqueous herbal extracts. Highest increase was in the fermented milk containing aqueous baheda extract $(49.79 \pm 0.23 \%)$, and lowest ACE inhibitory activity found in fermented milk containing aqueous arjuna extract (41.16 $\pm 0.95 \%)$. Nevertheless, no significant difference was observed between fermented milk containing aqueous harad and baheda extracts (Table 1).

Overall observation shows maximum ACE inhibitory activity in fermented milk containing aqueous arjuna extract (UD) and in aqueous harad extract (PD). The overnight digested samples demonstrated higher ACE inhibitory activity in fermented milk containing aqueous baheda extract (Figure 1). Plant-origin peptides can be generated by extraction of solvents, enzymatic hydrolysis with or without novel methods of food processing, and fermentation [18]. Several in vivo and in vitro studies have identified a range of medicinal plants which possess ACE inhibitory activity (Barbosa-Filho et al., 2006). Screening of these plants has identified several groups of natural ACE inhibitors including alkaloids, flavonoids, tannins, phenylpropanoids, proanthocyanidins, fatty acids, and terpenoids [25-26]. Crude extract of Ipomoea reniformis has hypotensive, ACE inhibitory and diuretic activities. The extract of $I$. reniformis produced 21.51 \pm 3.41 , $28.99 \pm 2.30,53.34 \pm 0.88$ and $61.71 \pm 3.37 \%$ fall in mean arterial blood pressure of the anesthetized rats at the doses of 0.1 , 0.3, 1.0 and $3.0 \mathrm{mg} / \mathrm{Kg}$, respectively. The above plant was found to have serum ACE inhibitory activity, with IC50 value of $422 \pm 21.16 \mu \mathrm{g} / \mathrm{mL}$.

\section{Conclusion}

Hypertension is a stern menace to human health and food-derived ACE inhibitory peptides can regulate it without any side effect. In the present study, undigested samples of fermented milk containing aqueous arjuna extract exhibited

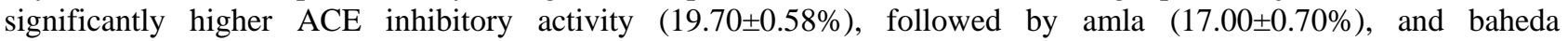
(16.59 $\pm 0.94 \%)$. Fermented milk containing aqueous harad extract had significantly lower value (14.97 $\pm 0.62 \%)$. Maximum (37.92 $\pm 0.72 \%)$ ACE inhibitory activity was observed in pepsin-digest of fermented milk containing aqueous harad extract, whereas minimum (25.37 $\pm 0.59 \%)$ ACE inhibitory activity was observed in fermented milk containing aqueous extract of amla. The present study exhibited that herbal extract supplemented fermented milk of the indigenous cattle can act as potential food-derived medicine. 


\section{References}

[1] Ibrahim, H. R., Ahmed, A. S., Miyata, T. (2017). Novel angiotensin-converting enzyme inhibitory peptides from caseins and whey proteins of goat milk. Journal of Advanced Research, 8: 63-71.

[2] Collins, R., MacMahon, S. (1994). Blood pressure, antihypertensive drug treatment and the risks of stroke and of coronary heart disease. British Medical Bulletin, 50: 272-298.

[3] Collins, R., Peto, R., MacMahon, S., Hebert, P., Fiebach, N. H., Eberlein, K. A. (1990). Blood pressure, stroke, and coronary heart disease. Lancet, 335(8693): 827-838.

[4] Duprez, D., Helshoecht, P. V., Eynde, W. V., Leeman, M. (2002). Prevalance of hypertension in the adult population of Belgium: Report of a worksite study, Attention Hypertension. Journal of Human Hypertension, 16: 47-52.

[5] James, P. A., Oparil, S., Carter, B. L., Cushman, W. C., Dennisonhimmelfarb, C., Handler, J., Lackland, D. T., LeFevre, M. L., MacKenzie, T. D., Ogedegbe, O. (2014). Evidence-based guideline for the management of high blood pressure in adults. The Journal of the American Medical Association, 311: 507-520.

[6] Grandi, A. M., Gaudio, G., Fachinetti, A., Bianchi, L., Nardo, B., Zanzi, P., Ceriani, L., Guasti, L., Venco, A. (1996). Hyperinsulinemia, family history of hypertension, and essential hypertension. American Journal of Hypertension, 9: 732-738.

[7] Cushman, D. W., Cheung, H. S. (1971). Spectrophotometric assay and properties of the angiotensin-converting enzyme of rabbit lung. Biochemical Pharmacology, 20: 1637-1638.

[8] Skeggs, L. T., Kahn, J. R., Shumway, N. P. (1956). The preparation and function of the hypertension-converting enzyme. Journal of Experimental Medicine, 103: 295-299.

[9] Ondetti, M. A., Rubin, B., Cushman, D. W. (1977). Design of specific inhibitors of Angiotensin-Converting Enzyme: New class of orally active antihypertensive agents. Science, 196: 441-444.

[10] Nakamura, Y., Masuda, O., Takano, T. (1996). Decrease of tissue angiotensin I-converting enzyme activity upon feeding sour milk in spontaneous hypertensive rats. Bioscience, Biotechnology, and Biochemistry, 60: 488-489.

[11] Pihlanto-Leppala, A. (2001). Bioactive peptides derived from bovine whey proteins: Opioid and ACE-inhibitory peptides. Trends in Food Science and Technology, 11: 347-356.

[12] Leclerc, P. L., Gauthier, S. F., Bachelardb, H., Santure, M., Roy, D. (2002). Antihypertensive activity of casein-enriched milk fermented by Lactobacillus helveticus. International Dairy Journal, 12: 995-1004.

[13] Angelo, A., Marco, C. (2001). Drug-induced angioedema without urticarial. Drug Safety, 24: 599-606.

[14] Chen, J., Wang, Y., Ye, R., Wu, Y., Xia, W. (2013). Comparison of analytical methods to assay inhibitors of angiotensin I-converting enzyme. Food Chemistry, 141: 3329-3334.

[15] Matsui, T., Matsufuji, H., Osajima, Y. (1992). Colorimetric measurement of angiotensin I-converting enzyme inhibitory activity with trinitrobenzene sulfonate. Bioscience, Biotechnology, and Biochemistry, 56: 517-518.

[16] Maruyama, S., Mitachi, H., Awaya, J., Kurono, M., Tomizuka, N., Suzuki, H. (2006). Angiotensin-I-converting enzyme inhibitory activity of the C-terminal hexapeptide of as1-casein. Bioscience, Biotechnology, and Biochemistry, 51: $2557-2561$.

[17] Hernandezledesma, B., Recio, I., Ramos, M., Amigo, L. (2002). Preparation of ovine and caprine $\beta$-lactoglobulin hydrolysates with ACE-inhibitory activity. Identification of active peptides from caprine $\beta$-lactoglobulin hydrolysed with thermolysin. International Dairy Journal, 12: 805-812.

[18] Daskaya-Dikmen, C., Yucetepe, A., Karbancioglu-Guler, F., Daskaya, H., Ozcelik, B. (2017). Angiotensin-I-Converting Enzyme (ACE)-inhibitory peptides from plants. Nutrients, 9(4): 316. doi: 10.3390/nu9040316. PMID: 28333109; PMCID: PMC5409655.

[19] Padghan, P., Mann, B., Sharma, R., Bajaj, R., Saini, P. (2017). Production of Angiotensin-I-Converting-Enzyme-Inhibitory Peptides in Fermented Milks (Lassi) Fermented by Lactobacillus acidophillus with Consideration of Incubation Period and Simmering Treatment. International Journal of Peptide Research and Therapeutics, 23: 69-79.

[20] Gouda, K. G. M., Gowda, L. R., Rao, A. G. A., Prakash, V. (2006). Angiotensin I-Converting Enzyme Inhibitory Peptide Derived from Glycinin, the 11S Globulin of Soybean (Glycine Max). Journal of Agriculture Food Chemistry, 54: $4568-4573$.

[21] Iwaniak, A., Minkiewicz, P., Darewicz, M. (2014). Food-Originating ACE Inhibitors, Including Antihypertensive Peptides, as Preventive Food Components in Blood Pressure Reduction. Comprehensive Reviews in Food Science and Food Safety, 13: 114-134.

[22] Boschin, G., Scigliuolo, G. M., Resta, D., Arnoldi, A. (2014). ACE-Inhibitory Activity of Enzymatic Protein Hydrolysates from Lupin and Other Legumes. Food Chemistry, 145: 34-40.

[23] Parrot, S., Degraeve, D., Couria, C., and Martial-Gros, A. (2003). In vitro study on digestion of peptides in Emmental cheese: Analytical evaluation and influence on angiotensin I converting enzyme inhibitory peptides. Nahrung/Food, 47: 87-94.

[24] Jimsheena, V. K., Gowda, L. R. (2009). Colorimetric, high-throughput assay for screening Angiotensin I-converting enzyme inhibitors. Analytical Chemistry, 81(22), 9388-9394.

[25] Loizzo, M. R., Said, A., Tundis, R., Rashed, K., Statti, G. A,, Hufnerm A., Menichini, F. (2007). Inhibition of angiotensin con- 
verting enzyme (ACE) by flavonoids isolated from Ailanthus excelsa (Roxb) (Simaroubaceae). Phytotherapy Research, 21(1): 32-36. doi: 10.1002/ptr.2008. PMID: 17072829.

[26] Nyman, U., Joshi, P., Madsen, L., Pedersen, T. B., Pinstrup, M., Rajasekharan, S., George, V., Pushpangadan, P. (1998). Ethnomedical information and in-vitro screening for angiotensin converting enzyme inhibition of plants utilized as traditional medicines in Gujarat, Rajasthan and Kerala (India). Journal of Ethnopharmacology, 60: 247-263. 